\title{
Application of Magnetic Material in the Underwater Power Tools
}

\author{
Zhang Hui1,2 \\ 1School of Naval Architecture and Ocean Engineering, Zhejiang Ocean University, Zhoushan, \\ Zhejiang, 316100, China.
}

2Key Laboratory of Offshore Engineering Technology of Zhejiang Province, China

Keywords: underwater power tools, magnetic effect, permanent magnets, impact mechanism.

\begin{abstract}
. ibration and the hurt produced by underwater power tools on operators, a new method, namely application magnetic materials in underwater power tools, was proposed. It analyses structure of common power tools, according to characteristics of permanent magnet, a novel of magnetic impact mechanism is designed based on magnetic effect principle, and the method is verified by an example of in this paper. Corresponding of conceptual design is proposed. The structure of permanent magnet is designed and calculated. The experimental result shows that the effectiveness of the application of magnetic material in underwater power tools.
\end{abstract}

\section{Introduction}

With growing economic, the importance of the exploitation of the sea is gradually drawing world attention, and the demand of underwater operations is increased[1,2]. The underwater power tool is small size and light weight, easy to carry and has a driving force for high power, is high efficiency and energy saving, so is widely used in marine geological survey, offshore oil exploration and exploitation, marine salvage, transport engineering and other underwater engineering work. Liu described the basic structure and working principle of hydraulic power source, water automatic pressure compensator was designed to eliminate the effects of deep pressure on tool system[3]. Meng introduced water-pressure automatic compensation for deep water hydraulic power source of the composition and working principle, analyzed the role of water automatic pressure compensator, determined compensator work volume, produced compensation methods that run underwater motor[4]. Cao analyzed electrical, pneumatic, hydraulic deep-compare power sources, and focused on two types of deep-sea hydraulic power source about hydraulic drive and hydraulic drive, summarized their characteristics and applications[5]. Yang analyzed and compared of the existing categories of machines tools for underwater operations based on the characteristics of focuses on salient advantage of the seawater hydraulic underwater operation tools[6]. How to reduce the vibration and the hurt produced by underwater power tools on operators wasn't discussed in these papers. Therefore, to complete underwater tasks by reliable and pollution free is the problem needed to solve about underwater power tools.

In this paper, based on the existing approach, we propose a new method, namely application magnetic materials in underwater power tools, was proposed. It analyses structure of common power tools, according to characteristics of permanent magnet, a novel of magnetic impact mechanism is designed based on magnetic effect principle, and the method is verified by an example of in this paper. Corresponding of conceptual design is proposed. The structure of permanent magnet is designed and calculated.

The paper is organized as follows. In the next section, we propose the problems of common power tools. In Section 3, conceptual design of underwater electric tools is presented. Finally, we conclude our paper in section 4.

\section{Existing problems of common power tools}

According to the principle of power tools, they can be divided into three types: Impact power tools, pneumatic power tools and electromagnetic power tools.

(1) Impact power tool 
Impact power tool is usually divided into two forms: tooth shape impact mechanism and rolling impact mechanism. Due to the relatively simple structure, the tooth shape impact mechanism is widely used in power tools. It is easy to operate but noisy.

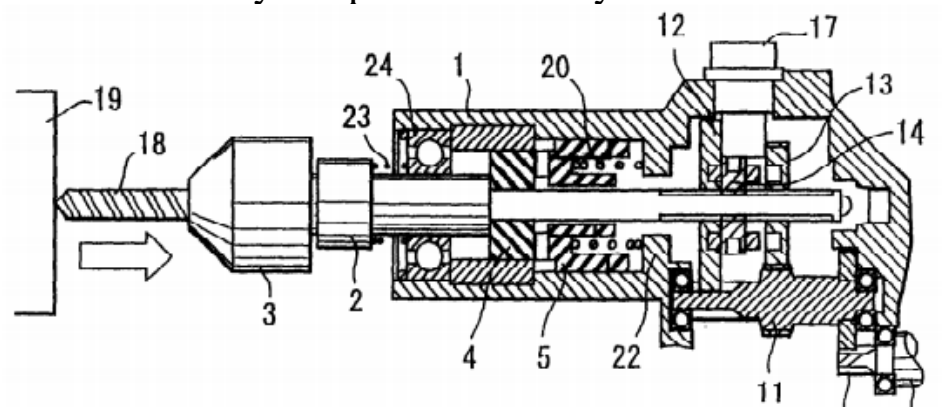

Fig.1: The ratchet hammer drill [7]

Fig. 1 is a ratchet drill, which will minimize the vibration is transmitted to the user holding the handle. Spindle is extended through the main frame, and can be moved along its axis and rotated around its axis. First ratchet could be rotated along with the spindle and axial movement. Second ratchet can be axial movement and cannot be rotated. When the impact mode is selected, first tooth surface is adjacent with the second tooth surfaces, so the spindle axially reciprocating motion.
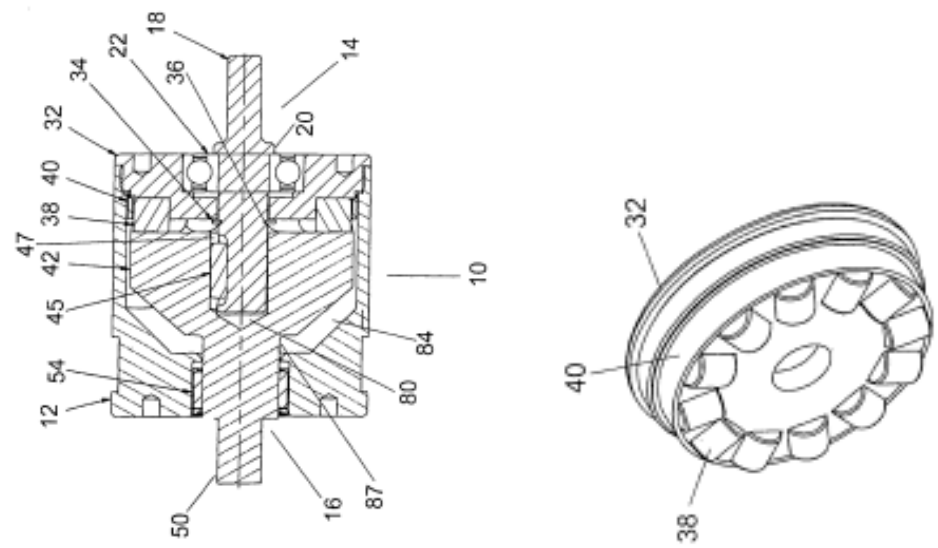

Fig.2 The rolling hammer drill [8]

A structure of ball impact drill is in Fig.2. A wave-like surface meshing is used between drive shaft and gear shaft structures in impact mechanism. Due to the use of ball bearings, so the contact area is almost zero, tooth surface can be used in a larger area.

(2) Pneumatic power tool

Pneumatic power tool is realized through the swing bearing bodies in impact exercise, or crank to achieve constantly reciprocating motion of the piston in the cylinder. It forms air cushion between the piston and plunger, and then the cushion makes impact motion of the head, back and forth to reach the final impact, such as in [9]. It is more powerful impact but high manufacturing costs.

(3) Electromagnetic power tool

Electromagnetic power tool is relied on electromagnetic solenoid as a source of power. The impact makes a campaign which uses the impact of spring behind the hammer. The drill is back and forth movement by retracting of the spring, such as literature [10]. It is simple structure but poor impact performance. 


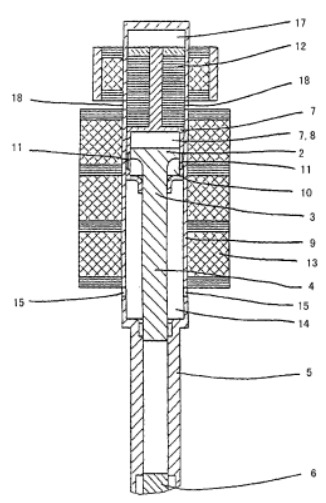

Fig.3: Impact mechanism with electric linear actuators[10]

Based on the above three forms of power tools of analysis, and the strengths and weaknesses of three forms of power tools as shown in Table 1.

Table 1: The strengths and weaknesses of three forms of power tools

\begin{tabular}{|l|l|l|}
\hline & \multicolumn{1}{|c|}{ strengths } & \multicolumn{1}{c|}{ weaknesses } \\
\hline $\begin{array}{l}\text { impact } \\
\text { power } \\
\text { tools }\end{array}$ & $\begin{array}{l}\text { Smaller, relatively small } \\
\text { quality, easy to operate, } \\
\text { safe, the more drilling } \\
\text { accurate }\end{array}$ & $\begin{array}{l}\text { friction heat, tooth wear, } \\
\text { short life, noisy }\end{array}$ \\
\hline $\begin{array}{l}\text { pneumat } \\
\text { ic power } \\
\text { tool }\end{array}$ & $\begin{array}{l}\text { structural stability, more } \\
\text { powerful impact, high } \\
\text { efficiency }\end{array}$ & $\begin{array}{l}\text { sealed } \\
\text { high-performance, high } \\
\text { manufacturing costs, } \\
\text { noisy, shorter life } \\
\text { expectancy, difficult to } \\
\text { repair energy }\end{array}$ \\
\hline $\begin{array}{l}\text { electrom } \\
\text { agnetic } \\
\text { power } \\
\text { tool }\end{array}$ & $\begin{array}{l}\text { easy to operate, } \\
\text { lightweight, simple } \\
\text { structure, easy to repair }\end{array}$ & $\begin{array}{l}\text { moreramption, short life, } \\
\text { poor impact } \\
\text { performance. }\end{array}$ \\
\hline
\end{tabular}

Taking into account different defects in the existing structures, and the magnetic materials are applied to underwater power tools in this paper, and a new kind of underwater power tool with a magnetic shock bodies is constructed.

\section{Conceptual Design of Underwater Electric Tools}

\subsection{Design Requirements of Underwater Electric Tools}

1) Finger grooves should not appear on the handle, otherwise the pressure on the man's finger[11].

2) Handle about $11 \sim 14 \mathrm{~cm}$ long while underwater; handle radius is typically between $1.6 \sim 2.3 \mathrm{~cm}$ and its width is $46 \mathrm{~cm}$ for the comfortable.

3) Highly sealed, waterproof.

4) Handle provides enough space, needs to match the staff size, easy to use and comfortable.

5) To keep your wrists straight when used, try to get palm force.

6) Keys for non-touch buttons.

7) Avoid repeated bending and loading easy.

\subsection{Characteristics of the Permanent Magnet}

Permanent magnets can be either natural or manufacture products. It is wide hysteretic, high coercive force and high reminisced magnetic. Once the magnetization, it is able to maintain a constant magnetic. In the application, permanent magnet should be high coercive force, reminisced magnetic and the maximum energy product, in order to ensure maximum storage of magnetic 
energy and stability of magnetic ${ }^{[11]}$. Permanent magnetic clutch transmission technology uses properties and the effect of the principle that a distance magnetic is exist between permanent magnets and magnetic and ferromagnetic materials. Now as a variety of shaft sealing technology and flexible mechanical drive technology, permanent magnetic transmission technology has been widely used.

\subsection{Design of Magnetic Impact Mechanism}

According to the characteristics of permanent magnet, magnetic impact mechanism is proposed in this paper. How it works is shown in Fig.4. The small surface of cone drive 10 is supported on housing 2 by the axle bearing 1 . The installed drill chuck is out shell. The big surface of cone drive 10 is provided with an annular groove. The groove with ring-shaped permanent magnet 4 and 5.The drive shaft is supported on the base 6 through the bearing 8 . At one end the drive shaft connected with the cone drive 10 by the key 3 through the base 6 . The container relative bearing of cone driver disk surface is provided with an annular groove. The groove mounts with ring-shaped permanent magnets. The interaction rotation between the circular permanent magnet 4 and the circular permanent magnet 5 makes suction and repulsion. The cone drive 10 drives shaft is back and forth to movement. On the other side of drive shaft is connected with the drive gear of motion transmission mechanism.

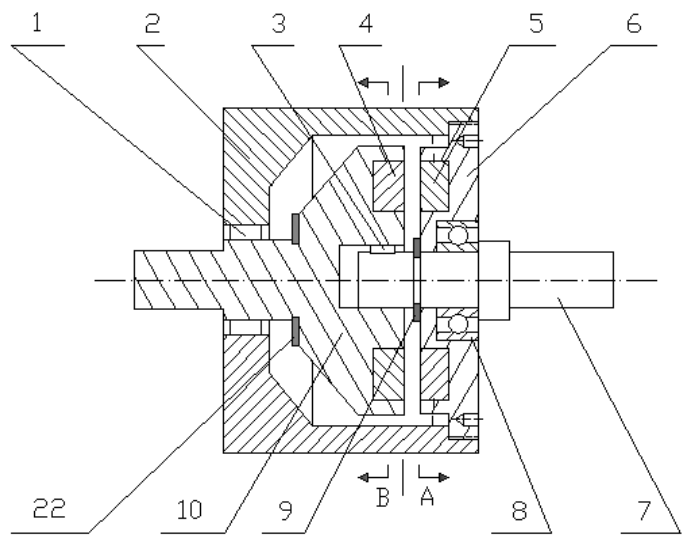

1, 8-bearing, 2-housing, 3-button, 4,5-permanent magnets, 6-base, 7-drive shaft, 9-ring, 10-cone drive, 22-rubber gaskets.

Fig.4: Diagram of the magnetic impact mechanism

Because the impact is produced with non-sealed and no particular sealing requirements of the institution, the structure is simple. Permanent magnets, which do not touch each other and without heat and wear issues, can greatly reduce the vibration and noise. Therefore, the energy is produced by the agency without friction losses. The hard impact will not exist between the parts and has long life and save oil. The structure does not generate dust and noise pollution during exercise.

\subsection{Design of Underwater Hammer Drill}

The underwater hammer drill is the most frequently used tool and used widely in underwater operations. Here to begin design with underwater hammer drill as an example.

\subsubsection{General Design}

In the design process, the key technical issues need to be addressed are:

(1) Driving permanent magnet on the driver disk, and making the shock impact motion. During exercise, that impact is needed to ensure without causing excessive vibration. The stability and sustainability of impact structures is maximized.

(2) Optimizing efficiently the structure of magnetic shocks. In the process of magnetic changes the maximum and minimum range is determined. All factors are taken into account in case of shock. The power tool is designed by magnetic impact mechanism as shown in the following figure. 


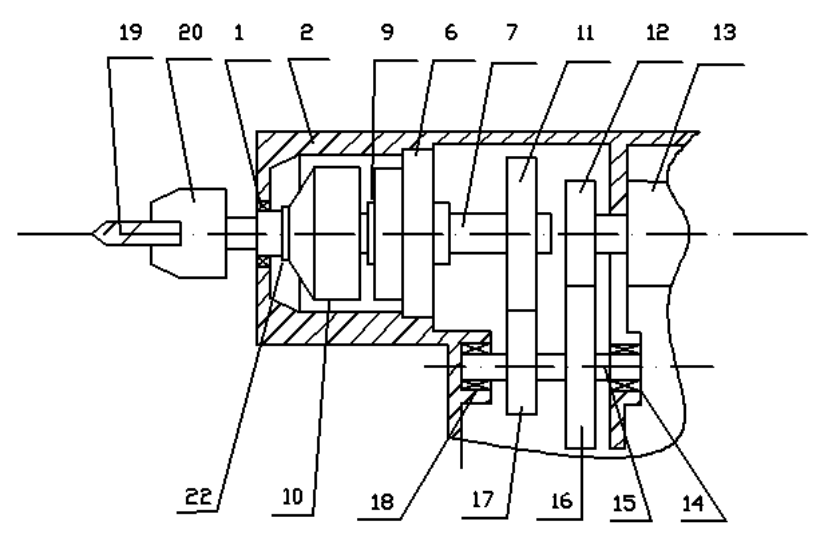

1-bearing, 2-shell, 3-key, 4, and 5-permanent magnet, 6-base, 7-drive axis, 8-bearing, 9-block circle, 10-cone drive, 11-drive gear, 12-motor gear, 13-motor, 14-bearing, 15-Middle axis, 16-Middle gear,

17-Middle small gear, 18-bearing, 19-bit, 20-drill clip head, 22-rubber washer.

Fig.5: The power tool with magnetic impact mechanism

As Fig. 5 shows, the motor 13 is in the impact drill of the shell 2 . When the motor 13 rotates, the motor gear 12 hat on the motor 13 meshes with the middle gear 16 that on the middle axis 15 . Two end of the middle axis 15 is supported in the bearing 14 and 18. The middle small gear 17 of the middle axis 15 is meshed with the drive gear 11 of the drive axis 7 , thus rotating movement is passed to the drive axis 7.

\subsubsection{Design of Permanent Magnet}

The shape of the permanent magnet is designed into four sectors, so that magnets can use the full surface area in rotation, as shown in Fig.6.

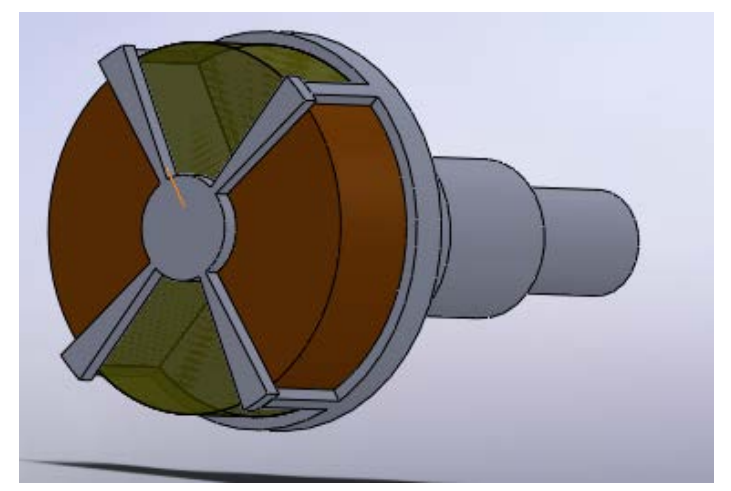

Fig.6: Magnet distribution

Inner radius of the fan-shaped permanent magnet $\mathrm{r} 2$ is $0.25 \mathrm{~cm}$, and outer radius $\mathrm{r} 1$ is $3.5 \mathrm{~cm}$. As shown in Fig.3. The magnets are relative distribution, when the space is divided into 4 parts. Angle is $96^{\circ}, 64^{\circ}, 96^{\circ}$ and $64^{\circ}$. The magnet surface area is:

$$
A_{g}=\pi\left(r_{1}-r_{2}\right)^{2} \frac{360^{\circ}-4 \times 10^{\circ}}{360^{\circ}}=29.5 \mathrm{~cm}^{2}
$$

After assembling the magnet as shown in Fig.7, the assignment status is shown. The red section is $\mathrm{N}$ pole in the picture, and the green section is $\mathrm{S}$ pole. The ratio of the surface area about the $\mathrm{N}$ and $\mathrm{S}$ pole is 3:2. Designed permanent magnet can be mounted on the driver's disk and the turning groove. It can be broken into several, and the frequency can be effectively increased. 


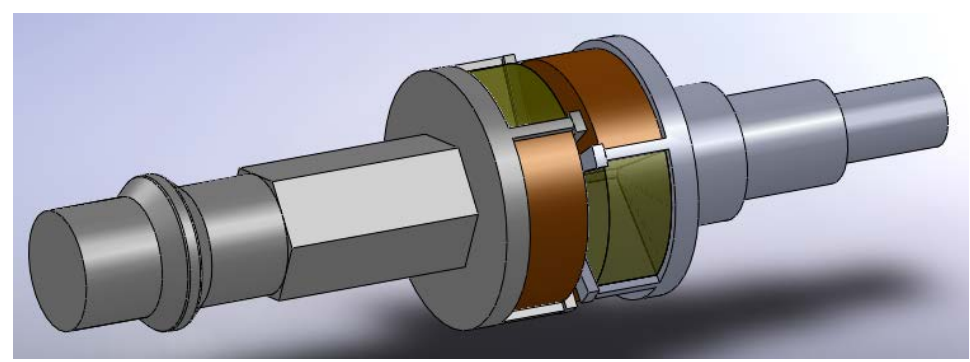

Fig. 7: Assembling the magnet

\section{Conclusions}

Based on magnetic principles, a method is proposed to design a novel magnetic impact mechanism based on the characteristics of permanent magnet. The method can be used for underwater power tools, and the application result is good. Through improving and optimizing, the magnetic impact mechanism can also be applied to other underwater power tools and has a great prospect in the field of underwater engineering.

\section{References}

[1] Zeng Ne, Hang Guan-Rong, Cao Guo-Hui, Present state and tendency of bionic underwater robot. Mechanical Engineer, 2006(4), pp. 18-21.

[2] Jiang Huai-You, Feng Pin, Li Zhi-Ping, Underwater oil-water separation technology of offshore oil industry abroad. Oil Knowledge, 2010(1), pp. 7-9.

[3] Liu Zhi-Hao, Gao Shi-Lun, Hydraulic power source of underwater tools development, Marine Technology, 2002(02), PP. 31-35.

4] Meng Qing-Xin, Wang Zhuo, Yuan Peng. \& Wang Li-Quan, Key techniques for underwater tools. Journal of Harbin Engineering University, 2002(1), pp. 76-79.

[5] Cao Xue-Peng, Wang Xue-Juan, Deng Bing, Ke Jian, Deep-sea development status and key technology of hydraulic power source. Marine Bulletin, 2010(04), pp. 24-27.

[6] Yang Shu-Dong, Li Zhuang-Yun, Yu Zu-Yao, Zhu Yu-Quan, Seawater hydraulic underwater operation tools, 1998 (02), pp. 12-15.

[7] Aito,S., Onder,P., Tsu,O. \& Unyi,R., Impact drill: China Patent 200410056338.5. (2004)

[8] Bob,H., Rolling hammer drill: U.S. Patent 7191848. (2007)

[9] Malmond,R., Hydraulic rotary percussive drilling: China Patent 03804472.2. (2003)

[10] Berg,R., Costanzo,O.W., Smead,W.,Impact mechanism with electric linear actuators: China Patent 200680022593.5. (2006)

[11] Denetsu,A., Kawasaki,R., Oscillating mechanism: China Patent 00117684.6. (2000) 